\title{
HOW LONG WILL IMPLANTS LAST?
}

The BDJ Upfront section includes editorials letters, news, book reviews and interviews.

Please direct your correspondence to the News Editor, David Westgarth at the BDJ, The Macmillan Building, 4 Crinan Street, London, N1 9XW or by email to BDJNews@nature.com

Press releases or articles may be edited, and should include a colour photograph if possible.

\author{
Stephen Hancocks OBE \\ Editor-in-Chief
}

Way back in the 1960s, when even I was a boy (I know, it seems unlikely) a huge craze swept the country. Domestic freezers (I know, that also seems highly unlikely and actually almost unthinkable in today's world). How could we not have had freezers at home? Fridges of course, but here was a new breed of appliances, big, brash, modern, musthaves which spawned any number of high street outlets, or shops as we called them then, selling not only the appliances but the huge sides of beef, legs of lamb and various other bulk foodstuffs with which to stock these cavernous monsters. The demand was there and over the many years in between the need has been adequately fulfilled so that apart from buying a new one when the old one goes wrong or the kitchen is being revamped then more or less everyone has one.

So, dental implants: are we about to experience a similar pattern? Is the bulk demand set to plummet? Remember that it is not so many years since the successful process of osseointegration through titanium was discovered and tested, yet in that time hundreds of thousands have been placed. But have the majority of people who need them now got them? There will of course be a continuing need, just as with freezers. There will be trauma to natural teeth, partial edentulousness due to genetic quirks, various anomalies of tooth development. Will the overall need continue at such a high rate though? With the increasing improvement in oral health in the sociodemographic groups who can afford implants, will there be enough gaps

\section{'How could \\ we not \\ have had \\ freezers at \\ home?'}

to keep all our existent and budding implantologists minding them?

Plus we have another issue to contend with. Not all implants last the course do they? The Dental Defence Union (DDU) recently announced that claims against dental professionals for dental implants are on the rise, with a $41 \%$ increase for the period from 2009-2013 in comparison to the previous five years. Additionally, of those claims settled to date, a not insignificant $€ 4$ million has been paid out. While there is every reason to suspect that other indemnity providers are experiencing similar situations, a total of 311 claims were received by the DDU in relation to dental implants in the 10 years 2004-2013, with 115 having been settled to date for an average of $£ 34,000$; one claim settling for over $£ 200,000$. The most common reason for claims was failure of treatment with over one third citing this as the reason for the claim, while unsatisfactory treatment was the second most common reason with $17 \%$ of claims alleging this. One wonders if this is the tip of what could be a very large iceberg.

Peri-implantitis is also something of a growing scourge. Although it is a gross generalisation, is it so surprising that people who have already lost some, a lot, or all of their teeth through dental disease may not be those who are ideal at keeping implants as artificial alternatives in any better condition? I suppose what I am asking is whether we have yet got over the major first flush of implant placement fever? Conversely there is an argument which says that of the multitude that have been placed many are functioning well and providing a vastly improved quality of life for patients, including the ability to eat a better diet and so improve their general as well as their oral health.

We have had correspondence in the journal warning about the perils of older people with debilitated health, perhaps with Alzheimer's, and who also have implants not being able to care for them adequately themselves. Care of the appliances should not be beyond the scope or skill of nursing personnel but additional education and training will be needed. Not a reason to deny the use of dental implants but another factor that must be considered as we learn more about the long term consequences of this treatment option.

Risk and benefit are the two seats at the ends of the see-saw and there is no doubt that the introduction of the dental implant has had hugely beneficial impacts. We do need to look at the risks though and it may be that, together with the falling actual need for implants there will also come a more balanced view as to where and when their placement gives the patient optimum positives for minimum negatives.

Those who made a successful and entirely ethical business in riding the wave of the freezer frenzy soon moved on to the next 'new thing', although I am dashed if I can remember what that was. In line with all the skills and services we currently offer or anticipate offering, providing dental implants may be ones for which we have to moderate our enthusiasms for a variety of both present and future reasons. Right, now, just time to defrost a ready meal.

DOI: 10.1038/sj.bdj.2015.726 